\title{
Global climate governance and transition to a low-carbon economy: a special issue of RBPI
}

EDUARDO VIOLA*

ANTÔNIO CARLOS LESSA**

Brazil may be considered one of the most important players in defining the great environmental agenda that involves national governments, the academia, and nongovernmental organizations (NGOs). This fundamental attribute is better yet noticed within the great public international debate that develops around issues related to climate change. At a time in which the United Nations Conference on Sustainable Development (UNCSD) was held in Rio de Janeiro, called Rio+20, which took place in June 13-22, 2012, in Rio de Janeiro city, we believe there would be no better pretext to organize a special edition of the Brazilian Journal of International Politics - Revista Brasileira de Politica Internacional (RBPI) - about this grand agenda.

This issue of RBPI is focused on the international political economy of climate change. All the articles consider climate change as one of the most relevant and urgent questions faced by humanity and the international system. Also, they agree about the strong dissonances between the recognition of the severity of the problem by all countries and the low effectiveness and slow pace of the international collective action to cope with it, so far.

We are grouping the articles in three types. The first group - four articles - deals with the general dynamic of the international system on climate change: the limits of climate governance in an international system under conservative hegemony; the contradictory performance of the G-8 countries; the role of G-77 and BASIC in the multilateral negotiations; and the conflict between the European Union and all the other major powers on taxation of global aviation. The second group - four articles - addresses the domestic and foreign climate policies of key

\footnotetext{
* Full Professor of International Relations at the University of Brasília (UnB) and Research Fellow of the National Council for Scientific and Technological Development (CNPq) (eduviola@gmail.com).

** Associate Professor of International Relations at the University of Brasília, editor of the Brazilian Journal of International Politics - Revista Brasileira de Politica Internacional (RBPI) - and Research Fellow of the National Council for Scientific and Technological Development (CNPq) (aclessa@gmail.com).
} 
players: United States of America, China, the European Union and Brazil. Finally, the third group - one article - focuses in the subnational climate governance: municipalities in the Brazilian Amazon.

The article Climate governance in an international system under conservative hegemony: the role of major powers by Viola, Franchini and Ribeiro defines the existence of eight major powers considering as criteria a high share of global carbon emissions and the availability of human and technological capital for the transition to a low-carbon economy: United States, China, European Union, India, Russia, Brazil, Japan and South Korea. Considering the effective behavior of the countries in terms of trajectory of carbon emissions and effective mitigation policies, the article finds a cleavage between the behavior of conservative countries (Russia and India) and moderate conservative countries (USA, China and Brazil) from one side and reformist countries (European Union, South Korea and Japan) from the other side.

The article Climate paradox of the G-8: legal obligations, policy declarations and implementation gap by Brauch analyzes the trajectory of G-8 countries in relation to their commitments in the Kyoto Protocol from 1997: relatively homogeneous for the G-7 and very singular in the case of Russia. The author finds five countries fulfilling the obligations (Germany, France, United Kingdom, Italy and Russia) and three countries with an implementation deficit (USA, Canada and Japan).

The article The G-77, BASIC, and global climate governance: a new era in multilateral environmental negotiations by Hochstetler analyzes the recent growing differentiation among Southern countries standing in negotiations, focusing in the formation of the BASIC coalition in 2009 and its impact in the traditional G-77 coalition. The major question of the article is whether differentiation of the South is now strong enough for changing the usefulness of the North/South framework for understanding climate governance.

The article Fighting climate change in the air: lessons from the EU directive on global aviation by Domingos analyzes an emblematic conflict in the present international political economy of climate change. The article describes the multiple dimensions of the conflict and finds three major factors explaining the situation: more progressive climate policy of the EU, concerns about competitiveness and legal inconsistence from all other major powers and perception of unilateral imposition by most countries.

The article An overview of domestic aspects in US climate policy by Ferreira, Ferreira and Vigevani analyzes domestic climate policy and politics during the Clinton, Bush and Obama administrations. The article shows increasing conservatism in domestic politics originated in diverse social and economic dynamics as a major factor in blocking progress in the international climate policy of USA and consequently in multilateral international negotiations. 
The article Dilemma of choice: China's response to climate change by Hung and Tsai analyzes various dilemmas faced by the Chinese elites facing responses to climate change: fast economic growth for consolidating as a new superpower and eliminating poverty versus the need of avoiding the blame for the stagnation on climate change negotiations; the fact that China is one of the most threatened countries by climate change and particularly extreme weather events versus the temptation that growing faster in the next decade could diminish the vulnerability of the country when the situation will become worse; the growing awareness about climate change in the national elites versus the drive to continuous fast economic growth in the local elites.

The article The European Union as an actor in global climate governance: meeting formal requirements, playing a role in practice by Pavese and Torney analyzes the unique role of the European Union in climate negotiations derived from grouping countries and having shared negotiation powers build up in a very complex process. The article provides a consistent theoretical framework related to the elements of actorness (recognition, capability, opportunity, and cohesion) and through empirical analyses of different historical periods, and it shows the power and limitations of the European Union as a leader on climate negotiations.

The article The Brazilian position on forests and climate change from 1997 to 2012: from veto to proposition by Carvalho analyzes the evolution of the Brazilian position on forest and climate change since 1997 to 2012, showing how the defensive and conservative position of Brazil in 1997 suffered a shift in the second half of the 2000s because of a combination of dramatic reduction in deforestation in the Amazon and changes in the relative force of domestic actors.

The article Governance of global climate change in the Brazilian Amazon: the case of Amazonian municipalities in Brazil by Inoue compares two dynamics in climate governance in Amazonian municipalities. The first one, top-down, has involved multiple actors and has been effective in reducing deforestation, but the municipalities have not had the capacity of shaping the outcome. In the second dynamic, bottom-up, which has also been effective and involved multiple actors, the municipalities have had the capacity of influencing the process more in correspondence with their particular situation and mindset. Inoue's article analyzing the dynamic of deforestation in the local level is fully convergent with Carvalho's focused in the national level.

There are major convergences among all the articles in the many aspects that addressed the same or similar issues. There is only one divergence, between Viola, Franchini and Ribeiro's article and Brauch's, in the assessment of the performance of Russia and Japan in their trajectory of emissions and general government behaviors because of the different conceptual frameworks used by both. 
This special edition is the result of a major international call, launched in October 2011. We were really pleased with the wide reception and repercussion that our initiative had, and we hope this historical edition of RBPI really contributes for the high-level reflection on the theme of climate change economics. 